\title{
PERHITUNGAN KEKUATAN RANGKA DISPENSER-LIFTER
}

\author{
Aditya Widhi Artanto \\ Departemen Teknik Mesin, Sekolah Vokasi, \\ Universitas Gadjah Mada \\ Email : aditya.widhi.a@mail.ugm.ac.id
}

\author{
Suryo Darmo*) \\ Departemen Teknik Mesin, Sekolah Vokasi, \\ Universitas Gadjah Mada \\ Email : suryo.darmo@ugm.ac.id \\ *corresponding author
}

\begin{abstract}
ABSTRAK
Pekerjaan mengangkat beban yang dilakukan manusia membutuhkan energi. Kebutuhan energi cukup besar untuk pekerjaan yang berat. Salah satu pekerjaan mengangkat yang sering dilakukan adalah mengangkat galon air minum ke atas dispenser yang posisinya tinggi. Pengangkatan air minum dalam kemasan galon ke dispenser tidak mudah dilakukan setiap orang. Karena hal tersebut, studi ini membuat meja dispenser yang bisa di geser naik turun dengan bantuan alat pengangkat berupa gear reducer, kawat sling dan penggulung. Meja dispenser diturunkan pada posisi terbawah pada saat memasang galon, sehingga dapat dilakukan dengan ringan. Penelitian ini dilakukan untuk menghitung kekuatan dispenserlifter, yang dilakukan pada bagian (titik) yang kritis. Desain disesuaikan untuk tingkat keamanan yang tinggi. Berdasarkan pengukuran dan kalkulasi kekuatan, didapatkan bahwa tegangan kombinasi sambungan las pada tiang penyangga sebesar 48,1 $\mathrm{N} / \mathrm{mm}^{2}$ dan pada titik kritis meja sebesar 18,42 $\mathrm{N} / \mathrm{mm}^{2}$. Tegangan ijin setiap sambungan las adalah $88 \mathrm{~N} / \mathrm{mm}^{2}$, sehingga alat aman untuk digunakan.

Kata Kunci: Tegangan ijin, titik kritis, dispenserlifter, galon, tegangan
\end{abstract}

\section{PENDAHULUAN}

Setiap manusia memiliki kekuatan berbeda untuk melakukan suatu kegiatan, terutama bila ditinjau dari segi gender atau usia. Seorang wanita atau orang tua tenaganya tidak terlalu besar sehingga akan beresiko dalam mengangkat suatu beban yang berat. Risiko cedera semakin besar apabila kegiatan dilakukan berulang ulang. Mengangkat galon ke atas dispenser yang cukup tinggi dapat menyebabkan terjadinya cedera sakit bahkan kecelakaan.

Dispenser umumnya diletakkan di atas meja agar saat membutuhkan air, posisi orang lebih nyaman dan tidak terlalu menunduk. Pengangkatan galon air ke atas dispenser yang cukup tinggi membutuhkan banyak tenaga. Memasang galon air di posisi rendah akan lebih ringan, namun hal itu tidak mungkin karena posisi dispenser akan terus di bawah. Posisi dispenser yang telah diberi galon harus lebih tinggi sesuai tingkat kenyamanan yang dibutuhkan. Oleh karena itu diperlukan dispenserlifter yaitu alat yang dirancang memiliki meja yang bisa digerakkan naik dan turun. Alat ini harus kuat dan aman agar tidak membahayakan pengguna.
Peneliti untuk membuat dan meneliti kekuatan rangka dispenser-lifter agar alat dijamin aman dan membantu mengatasi masalah risiko cedera. Alat ini sangat bermanfaat untuk rumah tangga. Penggunaan alat tidak memerlukan ketrampilan khusus karena pengoperasiannya sederhana. Alat dibuat untuk mengangkat dispenser dan galon kapasitas 19 liter dengan tinggi maksimal meja dispenser adalah 130 cm dari dasar lantai.

\section{TINJAUAN PUSTAKA}

Tegangan tarik terjadi bila ada gaya yang bekerja menarik komponen alat. Tegangan tekan sebaliknya terjadi saat ada gaya dari luar yang menekan. Selanjutnya, komponen alat akan mengalami tegangan lengkung bila alat tersebut mengalami momen lengkung. Momen tersebut terjadi bila suatu gaya bekerja pada jarak tertentu dari penampang yang ditinjau. Tegangan geser terjadi bila komponen alat mengalami beban sejajar dengan penampangnya [1].

Tegangan geser dan tegangan tarik yang bekerja secara bersamaan pada alat menghasilkan tegangan kombinasi [2]. Terkait dengan beban, penelitian ini dilakukan untuk menghitung:

1. Tegangan yang terjadi pada titik kritis batang penyangga.

2. Tegangan yang terjadi pada titik kritis meja.

\section{METODE PENELITIAN}

Penelitian dilakukan dalam tiga tahap, yaitu tahap desain serta persiapan alat dan bahan, tahap pembuatan alat dan tahap perhitungan kekuatan rangka dispenser-lifter.

Berikut tahapan penelitian yang lebih rinci.

1. Desain

Tahap ini dimulai dengan persiapan untuk perancangan dan pembuatan alat dispenserlifter. Survey lapangan dilakukan untuk mengetahui kondisi yang berhubungan dengan dispenser dan pemakaiannya serta kebutuhan untuk membuat dispenser-lifter. Pengumpulan data dikerjakan untuk menentukan ukuran, jenis material dan hal lain yang berpengaruh dalam penggunaan alat. Pekerjaan desain diselesaikan dengan menentukan rancangan alat agar memenuhi faktor keamanan, ergonomis dan estetika. Perangkat lunak yang dipakai dalam membuat desain adalah Solidwork. 
2. Pembuatan alat

Pembuatan alat dilakukan sesuai dengan desain yang telah dibuat. Bahan yang digunakan adalah material yang tersedia di pasaran. Proses pembuatan alat dilakukan di Laboratorium Bahan Teknik, Pengecoran dan Pengelasan, Departemen Teknik Mesin Sekolah Vokasi, Universitas Gadjah Mada

3. Perhitungan kekuatan

Proses ini menghitung gaya dan tegangan yang terjadi pada alat setelah dibuat dan digunakan. Setelah dapat dipastikan aman, uji coba dilakukan untuk memastikan alat bekerja sesuai rancangan.

\section{HASIL DAN PEMBAHASAN \\ Perancangan dispenser-lifter}

Dispenser-lifter (Gambar 1) dibuat dengan merancang model yang menyesuaikan hasil pengamatan lapangan sehingga sesuai untuk keperluan kegiatan sehari-hari. Bahan yang dipilih menggunakan baja hollow ukuran $30 \mathrm{~mm}$ x $60 \mathrm{~mm}$ dengan ketebalan $2 \mathrm{~mm}$, dilas menggunakan teknis las SMAW (Shielded Metal Arc Welding).

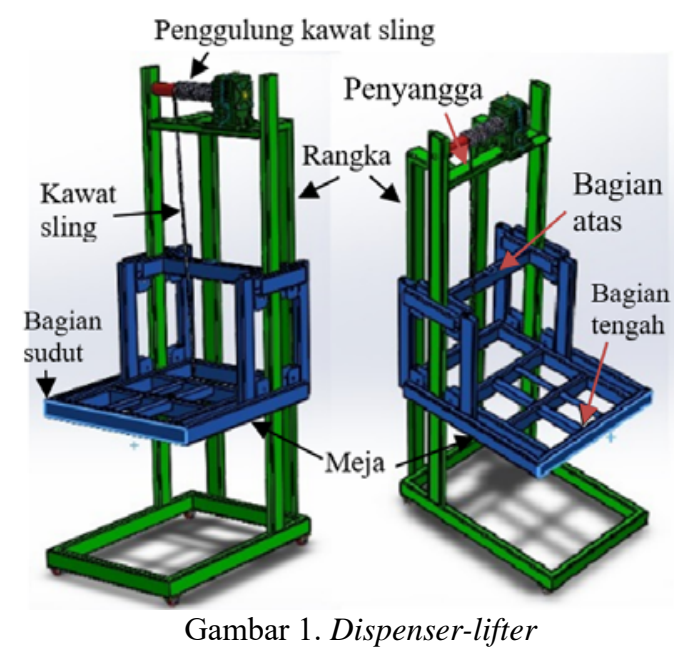

\section{Penggunaan elektroda las}

Elektroda yang digunakan pada sambungan las adalah seri E6010. Seri ini memiliki kekuatan tarik $\left(\sigma_{\mathrm{t}}\right)$ sebesar $43,6 \mathrm{~kg} / \mathrm{mm}^{2}$ dan kekuatan luluh $\left(\sigma_{\mathrm{y}}\right)$ sebesar $35,2 \mathrm{~kg} / \mathrm{mm}^{2}$ [4]. Angka keamanan yang digunakan adalah 4 sehingga tegangan tarik yang diijinkan adalah sebesar:

$\sigma_{\mathrm{ijin}}=\frac{43,6}{4} \mathrm{~kg} / \mathrm{mm}^{2}=8,8 \mathrm{~kg} / \mathrm{mm}^{2}=88 \mathrm{~N} / \mathrm{mm}^{2}$.

Besar tegangan geser yang diijinkan diambil setengah dari tegangan tarik ijin [5], sehingga tegangan geser ijin adalah sebesar:

$\tau_{\mathrm{ijin}}=\frac{88}{2} \mathrm{~N} / \mathrm{mm}^{2}=44 \mathrm{~N} / \mathrm{mm}^{2}$.

\section{Perhitungan kekuatan bagian kritis pada dispenser-lifter}

Dispenser-lifter dirancang agar dapat menahan beban tiba-tiba (hentakan) yang mungkin terjadi pada meja dan tiang penyangga. Rancangan pada bagian sudut meja adalah sebagai berikut:

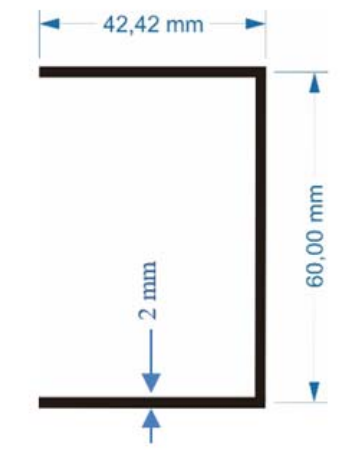

Gambar 2. Bentuk dan dimensi sambungan las pada bagian sudut meja.

Sudut meja merupakan bagian kritis pada alat ini yang harus diketahui nilai kekuatannya. Gambar 2 menunjukkan bentuk sambungan las baja hollow pada bagian sudut meja. Sisi atas dan bawah memiliki panjang las masing-masing $42,42 \mathrm{~mm}$, dan sedangkan sisi lainnya adalah $60 \mathrm{~mm}$. Tebal lasan pada bagian yang disambung adalah $2 \mathrm{~mm}$, sehingga luas penampang lasan adalah sebesar:

$$
\mathrm{A}_{1}=144,84 \mathrm{~mm} \times 2 \mathrm{~mm}=289,68 \mathrm{~mm}^{2} .
$$

Besar gaya yang yang mungkin terjadi pada bagian sudut meja adalah $100 \mathrm{~kg}$ atau $1000 \mathrm{~N}$. Tegangan geser yang terjadi adalah sebesar:

$$
\tau=\frac{1000}{289,68} \mathrm{~N} / \mathrm{mm}^{2}=3,452 \mathrm{~N} / \mathrm{mm}^{2} .
$$

Karena tegangan geser yang terjadi lebih kecil dari tegangan geser ijin $\left(44 \mathrm{~N} / \mathrm{mm}^{2}\right)$, maka sambungan las ini aman.

Sambungan las pada bagian tengah meja dispenser-lifter juga mendapatkan beban yang cukup besar. Sambungan las dibuat dengan bentuk dan dimensi sambungan seperti ditunjukkan pada Gambar 3. Panjang sisi atas dan bawah masingmasing adalah $30 \mathrm{~mm}$ dan panjang sisi lainnya adalah $60 \mathrm{~mm}$, sedangkan tebal lasan dibuat sebesar $2 \mathrm{~mm}$. Luas penampang sambungan las adalah sebesar:

$$
\mathrm{A}_{2}=120 \mathrm{~mm} \times 2 \mathrm{~mm}=240 \mathrm{~mm}^{2} .
$$




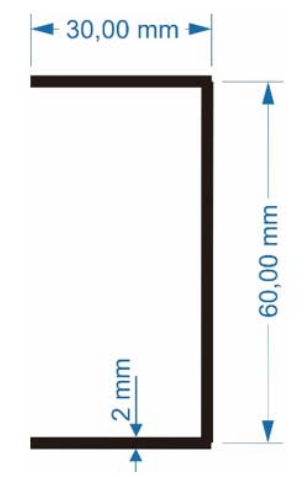

Gambar 3. Bentuk dan dimensi sambungan las pada bagian tengah meja.

Besar gaya untuk perhitungan tegangan yang terjadi pada bagian tengah meja adalah $100 \mathrm{~kg}$ atau $1000 \mathrm{~N}$. Tegangan geser yang terjadi adalah sebesar:

$$
\tau=1000 \mathrm{~N} / 240 \mathrm{~mm}^{2}=4,167 \mathrm{~N} / \mathrm{mm}^{2} .
$$

Tegangan geser ini lebih kecil dari tegangan geser ijin (44 N/mm2), sehingga sambungan las aman.

Bagian atas meja dispenser-lifter selain mengalami tegangan geser juga mengalami tegangan bending tarik. Sambungan las dibuat dengan bentuk dan dimensi seperti ditunjukkan pada Gambar 4. Panjang sisi atas dan bawah masingmasing adalah $30 \mathrm{~mm}$ sedangkan panjang sisi kiri dan kanan adalah $60 \mathrm{~mm}$ Tebal lasan dibuat sebesar $2 \mathrm{~mm}$. Luas penampang sambungan las adalah:

$$
\mathrm{A}_{3}=180 \mathrm{~mm} \times 2 \mathrm{~mm}=360 \mathrm{~mm}^{2} .
$$

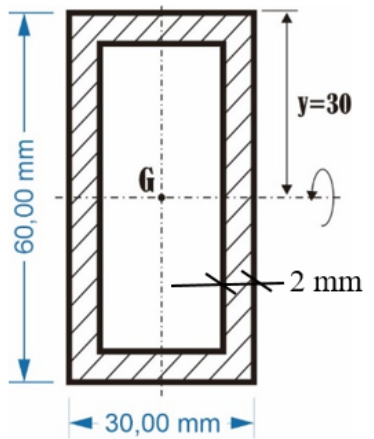

Gambar 4. Bentuk dan dimensi sambungan las pada bagian atas meja.

Besar gaya yang digunakan untuk perhitungan tegangan yang terjadi pada bagian atas meja adalah $100 / 2 \mathrm{~kg}$ atau sama dengan $50 \mathrm{~kg}$. Tegangan geser tersebut sebesar:

$$
\tau=\frac{50}{360} \mathrm{~kg} / \mathrm{mm}^{2}=0,139 \mathrm{~kg} / \mathrm{mm}^{2} .
$$

Momen inersia penampang sambungan las pada Gambar 4 adalah sebagi berikut:

$$
\begin{gathered}
\mathrm{I}=(1 / 12)\left\{(30 \mathrm{~mm}) \times(60 \mathrm{~mm})^{3}-(26 \mathrm{~mm}) \times(56\right. \\
\left.\mathrm{mm})^{3}\right\}=159.498,67 \mathrm{~mm}^{4} .
\end{gathered}
$$

Momen yang terjadi, $\mathrm{M}=50 \mathrm{~kg} \times 195 \mathrm{~mm}=9750$ kg.mm. Jarak titik yang ditinjau dari garis netral atau sumbu penampang, $\mathrm{Y}=30 \mathrm{~mm}$.

Tegangan tarik bending yang terjadi adalah:

$$
\begin{aligned}
& \sigma_{b}(+)=\frac{9750 \mathrm{~kg} \cdot \mathrm{mm} \times 30 \mathrm{~mm}}{159.498,67 \mathrm{~mm}^{4}} \\
& \sigma_{b}(+)=1,8334 \mathrm{~kg} / \mathrm{mm}^{2} .
\end{aligned}
$$

Tegangan kombinasi dari tegangan geser dan tegangan tarik bending dihitung dengan persamaan berikut:

$$
\begin{aligned}
& \sigma_{c}=\frac{1,8334 \mathrm{~kg} / \mathrm{mm}^{2}}{2}+ \\
& \sqrt{\left(\frac{1,8334 \mathrm{~kg} / \mathrm{mm}^{2}}{2}\right)^{2}+\left(0,139 \frac{\mathrm{kg}}{\mathrm{mm}^{2}}\right)^{2}} \\
& \sigma_{c}=1,842 \mathrm{~kg} /\left(\mathrm{mm}^{2}\right)=18,42 \mathrm{~N} / \mathrm{mm}^{2}
\end{aligned}
$$

Nilai tegangan kombinasi lebih kecil dari tegangan tarik ijin $\left(88 \mathrm{~N} / \mathrm{mm}^{2}\right)$, maka sambungan las ini aman.

Penyangga adalah komponen yang memiliki tegangan yang paling riskan karena menerima beban meja dan dispenser serta galon air. Gambar 5 menunjukkan bagian kritis dari penyangga saat menerima tegangan bending tarik dan geser. Bentuk dan dimensi sambungan las pada penyangga ditunjukkan pada Gambar 6. Momen inersia penampang dihitung dengan tahapan membagi luasan penampang lasan menjadi tiga bagian (luasan yang diarsir), kemudian mencari titik berat penampang total, dan menghitung harga y. Tahap berikutnya adalah mencari momen inersia penampang masing-masing bagian (yang diarsir) kemudian mencari momen inersia penampang total.

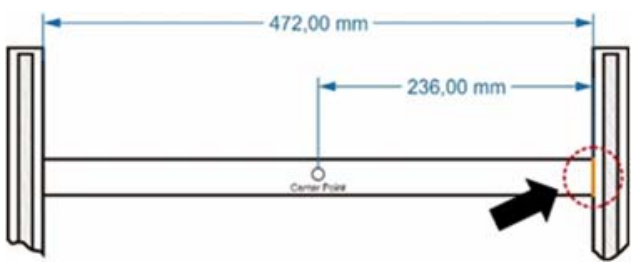

Gambar 5. Daerah Kritis Batang Penyangga.

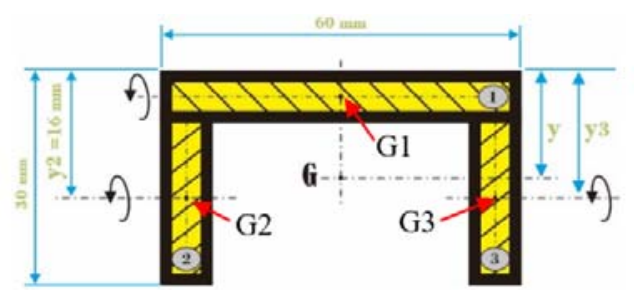

Gambar 6. Bentuk dan dimensi sambungan las pada batang penyangga. 
Masing-masing bagian mempunyai luas penampang A1, A2, dan A3, titik berat G1, G2, dan G3, jarak titik yang ditinjau $\mathrm{Y} 1, \mathrm{Y} 2$, dan $\mathrm{Y} 3$, dan momen inersia penampang $\mathrm{I}_{1}, \mathrm{I}_{2}$, dan $\mathrm{I}_{3}$. Gambar 7 adalah bagian atau daerah 1 . Gambar 8 adalah bagian 2 dan bagian 3 .

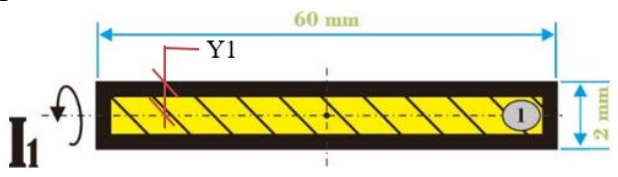

Gambar 7. Bagian atau daerah 1 sambungan las pada Gambar 6.

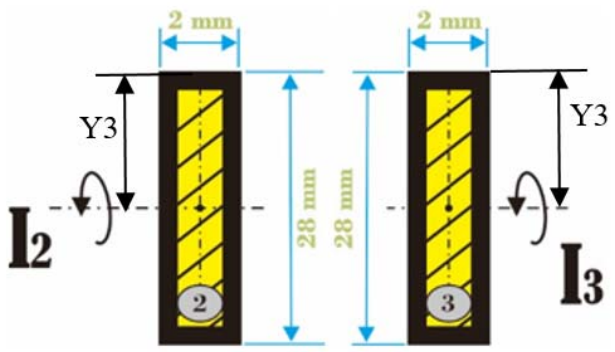

Gambar 8. Bagian atau daerah 2 dan 3 sambungan las pada gambar 6 .

Dari Gambar 6 hingga 8, luas masing-masing bagian adalah:

$$
\begin{aligned}
& \mathrm{A} 1=2 \times 60=120 \mathrm{~mm}^{2} \\
& \mathrm{~A} 2=2 \times 28=56 \mathrm{~mm}^{2} \\
& \mathrm{~A} 3=2 \times 28=56 \mathrm{~mm}^{2}
\end{aligned}
$$

Harga $y 1=1 \mathrm{~mm}, y 2=16 \mathrm{~mm}, y 3=16 \mathrm{~mm}$ sehinnga didapatkan nilai y sebagai berikut:

$$
\begin{gathered}
y=\frac{A 1 \cdot y 1+A 2 \cdot y 2+A 3 \cdot y 3}{A 1+A 2+A 3} \\
y=\frac{120 \times 1+56 \times 16+56 \times 16}{120+56+56}=8,24 \mathrm{~mm}
\end{gathered}
$$

Jarak titik berat penampang bagian terhadap titik berat penampang total dinyatakan dengan $\mathrm{H}, \mathrm{H} 2$, dan H3. Dari Gambar 9 didapat $\mathrm{H} 1=7,24 \mathrm{~mm}, \mathrm{H} 2$ 7,76 $\mathrm{mm}$, dan $\mathrm{H} 3=7,76 \mathrm{~mm}$.

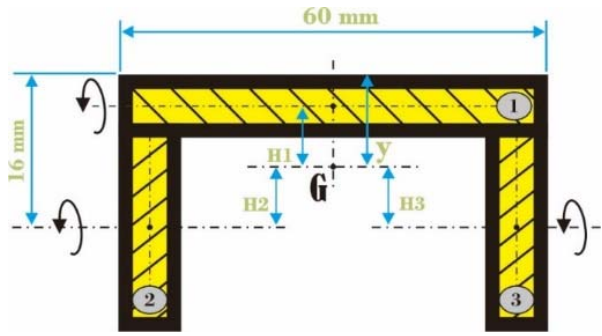

Gambar 9. Jarak titik berat penampang bagian terhadap titik berat penampang total.
Momen inersia penampang masing-masing bagian:

$$
\begin{aligned}
\mathrm{I}_{1} & \left.=\left(\frac{1}{12}\right)(60 \mathrm{~mm})(2 \mathrm{~mm})^{3}\right) \\
\mathrm{I}_{1} & =40 \mathrm{~mm}^{4} . \\
\mathrm{I}_{2} & =\left(\frac{1}{12}\right)(2 \mathrm{~mm})(28 \mathrm{~mm})^{3} \\
\mathrm{I}_{2} & =3658,66 \mathrm{~mm}^{4} . \\
\mathrm{I}_{3} & =\left(\frac{1}{12}\right)(2 \mathrm{~mm})(28 \mathrm{~mm})^{3} \\
\mathrm{I}_{3} & =3658,66 \mathrm{~mm}^{4} .
\end{aligned}
$$

Momen inersia penmpang total dihitung dengan persamaan berikut:

$$
\begin{aligned}
I= & \left(I_{1}+A 1 H_{1}^{2}\right)+\left(I_{2}+A 2 H_{2}^{2}\right)+\left(I_{3}+A 3 H_{3}^{2}\right) \\
I= & \left(40+120 \times 7,24^{2}\right)+\left(3658,66+56 \times 7,76^{2}\right)+ \\
& \left(3658,66+56 \times 7,76^{2}\right)=20391,79 \mathrm{~mm}^{4} .
\end{aligned}
$$

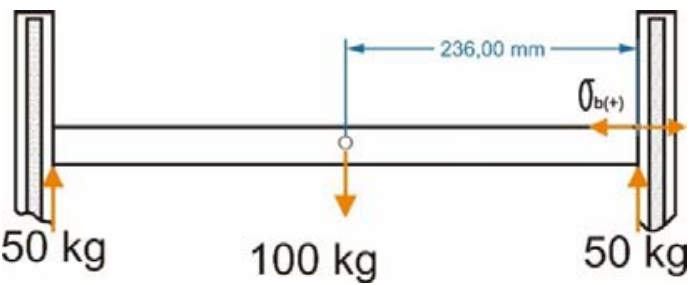

Gambar 10. Pembebanan pada penyangga.

Penyangga dirancang menahan gaya berat yang akan ditempatkan di meja sebesar100 kg. , dimana kedua titik kritis dari bagian atas penyangga meja menerima masing-masing $50 \mathrm{~kg}$ beban gaya. Momen dari bagian tersebut adalah $50 \mathrm{~kg}$ x $236 \mathrm{~mm}$, yaitu sebesar $11800 \mathrm{~kg} . \mathrm{mm}$. Tegangan tarik bending yang dialami oleh penyangga adalah sebesar:

$$
\sigma \mathrm{b}(+)=\frac{\mathrm{M} \cdot \mathrm{Y}}{\mathrm{I}}
$$

Dengan: $\mathrm{M}=11800 \mathrm{~kg} \cdot \mathrm{mm}$

$$
\begin{aligned}
& \mathrm{Y}=8,24 \mathrm{~mm} \\
& \mathrm{I}=20391,79 \mathrm{~mm}^{4}
\end{aligned}
$$

Maka, $\sigma_{b}(+)=\frac{(11800 \mathrm{~kg} \cdot \mathrm{mm} \times 8,24 \mathrm{~mm})}{20391,79 \mathrm{~mm}^{4}}$

$$
\sigma_{b}(+)=47,68 \mathrm{~N} / \mathrm{mm}^{2}
$$

Selain tegangan tarik, di bagian sisi atas sambungan las juga terdapat tegangan geser yang harus ditahan oleh sambungan las. Luas penampang lasan total $=\mathrm{A} 1+\mathrm{A} 2+\mathrm{A} 3=232 \mathrm{~mm}^{2}$, sehingga tegangan geser yang terjadi adalah:

$$
\tau=\frac{50 \mathrm{~kg}}{232 \mathrm{~mm}^{2}}=0,215 \mathrm{~kg} / \mathrm{mm}^{2} \text {. }
$$


Tegangan kombinasi dari tegangan geser dan tegangan tarik bending dihitung dengan persamaan berikut:

$$
\begin{aligned}
& \sigma c=\frac{\sigma b(+)}{2}+\sqrt{\left(\frac{\sigma b(+)}{2}\right)^{2}+\sigma^{2}} \\
& \sigma c=\frac{4,768}{2}+\sqrt{\left(\frac{4,768}{2}\right)^{2}+(0,215)^{2}} \\
& \sigma c=4,81 \mathrm{~kg} / \mathrm{mm}^{2}=48,1 \mathrm{~N} / \mathrm{mm}^{2}
\end{aligned}
$$

Karena tegangan kombinasi yang terjadi lebih kecil dari tegangan tarik ijin $\left(88 \mathrm{~N} / \mathrm{mm}^{2}\right)$, maka sambungan las ini aman.

\section{KESIMPULAN}

Berdasarkan penelitian yang sudah dilakukan untuk desain dan perhitungan kekuatan dispenserlifter maka dapat diambil kesimpulan sebagai berikut:

1. Alat dispenser-lifter dapat membantu kegiatan sehari-hari, mengurangi beban tenaga yang dibutuhkan saat mengangkat galon $\mathrm{ke}$ atas dispenser yang ada pada meja. Hal ini dikarenakan posisi meja bisa diturunkan ke bawah.

2. Tegangan yang terjadi adalah aman untuk beban nominal sebesar100 kg.

3. Tegangan yang terjadi pada bagian kritis penyangga dispenser-lifter berdasarkan perhitungan yang dilakukan adalah sebesar 48,1 $\mathrm{N} / \mathrm{mm}^{2}$.

4. Tegangan yang terjadi pada bagian kritis meja geser dispenser-lifter berdasarkan perhitungan sebesar 18,42 N/mm².

5. Alat dispenser-lifter aman untuk digunakan dalam kehidupan sehari-hari

\section{REFERENSI}

[1] Dupen, B., 2014, Applied Strength of Material for Engineering Technology, 6th Ed., Indiana.

[2] Khurmi, R. S. and Gupta, J. K., 2005, Machine Design, 14 ${ }^{\text {th }}$ Ed., Eurasia Publishing House (PVT.) Ltd., New Delhi.

[3] Sarojo, A. G., 2005, Mekanika, Edisi 4, Salemba Teknika, Jakarta.

[4] Wiryosumarto, H. dan Okumura, T., 2000, Teknologi Pengelasan Logam, Edisi 8, Pradnya Paramita.

[5] Dieter, G.E., 1988, Mechanical Metallurgy. $1^{\text {st }}$ Ed., McGraw Hill, London. 